\section{Nutrition is a hard science}

\section{Martin Kohlmeier}

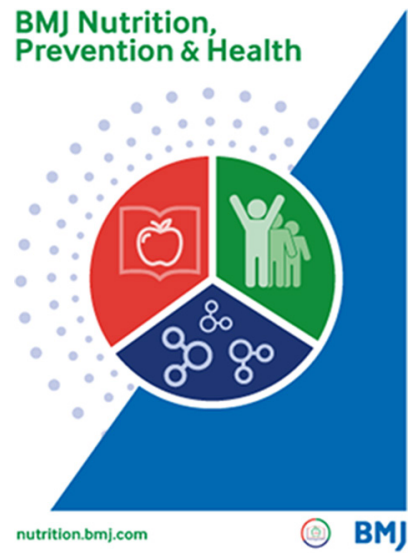

There have been a lot of questions about the reliability of nutritional science. We should respond with an assertive statement: Nutrition is a hard science. By just about any comparison, much of what is known about nutrition and the methods that have built that knowledge is as robust as classical physics, biochemistry and other basic sciences generally recognised as rigorous. We know how people handle hundreds of dietary compounds, understand many of the mechanisms and pathways, and are usually able to predict metabolic responses to lack or excess. If somebody wants to know which foods are good sources of vitamin $B_{12}$ and how it gets from ingested food into the bloodstream, we can be confident that the answer today will be the same as 50 years from now. The knowledge about this and many other specific nutrition concepts can be justifiably considered mature with low likelihood to change materially.

We can also predict with confidence that vitamin $B_{12}$ stores will decline without any source of vitamin $B_{12}$, say in a person with a vegan food intake pattern not using dietary supplements, although it may take decades to reach the point of deficiency. It is easy enough to prevent vitamin $B_{12}$ deficiency with food supplementation for people at risk. Biomarkers like methylmalonic acid (MMA) concentration in

Correspondence to Martin Kohlmeier, School of Medicine, Gillings School of Global Public Health, Nutrition Research Institute, University of North Carolina at Chapel Hill, Chapel Hill, NC 27599, USA; mkohlmeier@unc.edu plasma help to recognise deficiency when intakes are too low and serve as the basis for setting dietary targets. Elevated MMA concentrations are common in elderly people due to poor nutrition, ${ }^{12}$ sometimes aggravated by renal insufficiency which slows MMA excretion. ${ }^{3}$ In rare cases, vitamin $B_{12}$ losses may be greater and faster than expected, such as with failure of vitamin $B_{12}$ absorption due to autoantibodies against gastric parietal cells or intrinsic factor. ${ }^{4}$

'We will not shy away from difficult topics, but will work hard to avoid the fad of the day.'

All of this can be very challenging in practice because of the many different factors involved, some of which may not be known or fully understood. But these challenges are not fundamentally different from those in other hard science disciplines. The scientific rigour is usually maintained by corrective actions when encountering deviations from the predicted behaviour. Under the best of circumstances, detailed study and testing of the non-conforming observations will eventually lead to resolution and advance. It is important to recognise, however, that scientific advances also have been painfully slow in other disciplines.

\section{NOT FOR THE FAINT-HEARTED}

This takes us to another meaning when we call nutrition a hard science: It is difficult to do, requires significant resources, and can lead astray before providing clarity. It is definitely not an undertaking for faint-hearted and easily discouraged researchers. Careful study and the acquisition of required skillsets are essential.

Nutrition concerns most aspects of modern medical practice with added doses of behavioural science, psychology, food science, law and policy. Physicians cannot serve their patients without preparing extensively to understand and deal with at least the most typical nutritional scenarios in practice.

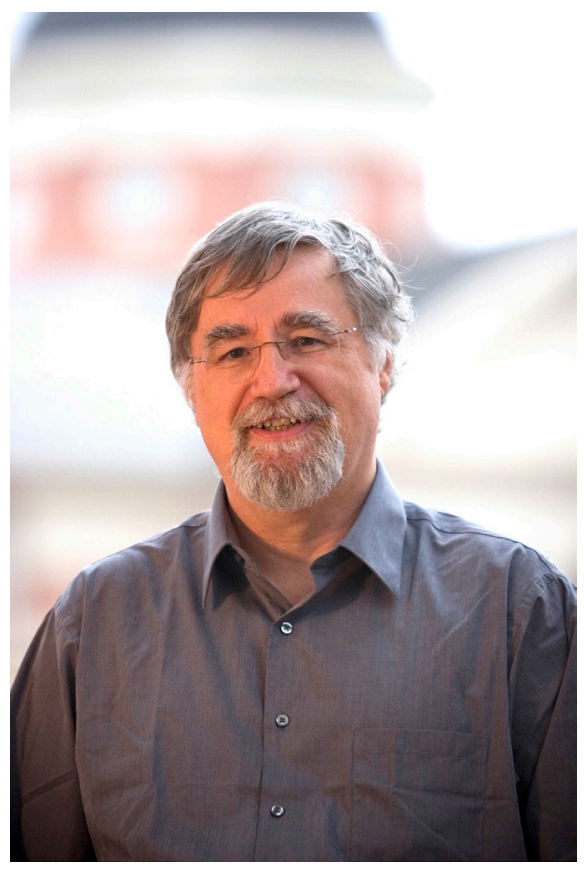

Will they know enough to understand that vitamin $B_{12}$ deficiency can accelerate the cognitive decline of their elderly patient in the early stages of Alzheimer's disease, ${ }^{5}$ and will they be ready to initiate the appropriate assessments and interventions? What about exposure to nitrous oxide during routine anaesthesia or for recreational purposes ${ }^{6}$ ? This is not to suggest that vitamin $B_{12}$ is of particularly eminent significance. There are many more complex knowledge items where this one is coming from.

Yet another double entendre reminds us that nutrition can be a harsh mistress for those entering the field with optimism and best intentions. The aspersions particularly from the lay public can be very discouraging, the competition from less informed colleagues frustrating. Finally, for the end users of the science, the patients and clients, restrictions and intolerances often impose tough burdens. Determined and dedicated development efforts are urgently needed to make it easier and more bearable to deal with their dietary regimen.

\section{BETTER SCIENCE MAKES FOR BETTER OUTCOMES}

The bright side is that better science makes in many cases for demonstrably better outcomes, both for treatment and prevention. We may well be experiencing a watershed moment in the history of nutrition research and 
practice. The potential for better health through nutrition and lifestyle has never been greater. At the same time, the coming generation may be the first in recent history that is less healthy than the previous one and has a shorter life span. The direction we take in the health professions will probably impact populations near and far for a long time to come. We can continue to enjoy the titillations of stunning research reports and then continue to ignore at our own peril the compelling lessons in daily practice and our own lives. Or we can ride a wave of better knowledge and understanding toward continued health gains and greater well-being.

\section{REDUCING THE BOTTLENECK}

The motivation to take on the development of yet another nutrition journal feeds on the realisation that disseminating high-end research to practitioners is the bottleneck of nutrition science. It will not matter that research develops exponentially if the spout for dissemination remains narrow and limiting. I expect this new entry into the nutrition, prevention and health market to get game-changing information out to practitioners with fresh themes, timely reports, and compelling stories. We consider globally accessible delivery of impactful and trustworthy nutrition information our singular goal. While breakthrough discoveries have their undeniable appeal, this journal will value especially contributions that advance practical and evidence-supported nutrition solutions for urgent health challenges.

Another key consideration will be to deliver information that practitioners need. For this we will actively seek the input of the health community. We want to hear what would be most useful for those that can translate new knowledge into better health of their communities. This will help to then engage with researchers and seek high-quality contributions responsive to the recognised priorities. Sometimes articles will have to address prevalent misconceptions, myths and malpractice. We will not shy away from difficult topics, but will work hard to avoid the fad of the day. Our measure of success will be the adoption of more effective practices by healthcare professionals and the journal metrics will follow.

Funding The authors have not declared a specific grant for this research from any funding agency in the public, commercial or not-for-profit sectors.

Competing interests None declared.

Patient consent Not required.

Provenance and peer review Commissioned, not externally peer reviewed.

\section{(2) OPEN ACCESS}

Open Access This is an Open Access article distributed in accordance with the Creative Commons Attribution Non Commercial (CC BY-NC 4.0) license, which permits others to distribute, remix, adapt, build upon this work non-commercially, and license their derivative works on different terms, provided the original work is properly cited and the use is non-commercial. See: http://creativecommons.org/ licenses/by-nc/4.0

(C) Author(s) (or their employer(s)) 2018. Re-use permitted under CC BY-NC. No commercial re-use. See rights and permissions. Published by BMJ.

\section{Check for updates}

To cite Kohlmeier M. bmjnph 2018;1:1-2.

Published Online First 17 July 2018

bmjnph 2018;1:1-2.

doi:10.1136/bmjnph-2018-000001

\section{REFERENCES}

1 Green R, Allen LH, Bjørke-Monsen A-L, et al. Vitamin B12 deficiency. Nat Rev Dis Primers 2017;3:17040.

2 Conzade R, Koenig W, Heier M, et al. Prevalence and predictors of subclinical micronutrient deficiency in german older adults: results from the population-based KORA-age study. Nutrients 2017;9:E1276.

3 van Loon SL, Wilbik AM, Kaymak U, et al. Improved testing for vitamin $\mathrm{B}_{12}$ deficiency: correcting MMA for eGFR reduces the number of patients classified as vitamin $B$ deficient. Ann Clin Biochem 2018;456321877 8300:000456321877830.

4 Khan S, Del-Duca C, Fenton E, et al. Limited value of testing for intrinsic factor antibodies with negative gastric parietal cell antibodies in pernicious anaemia. $J$ Clin Pathol 2009;62:439-41.

5 Cho HS, Huang LK, Lee YT, et al. Suboptimal baseline serum vitamin B12 is associated with cognitive decline in people with alzheimer's disease undergoing cholinesterase inhibitor treatment. Front Neurol 2018;9:325

6 Egan W, Steinberg E, Rose J. Vitamin $\mathrm{B}_{12}$ deficiency-induced neuropathy secondary to prolonged recreational use of nitrous oxide. Am J Emerg Med 2018;6757:S073530406-6. 